\title{
AVALIAÇÃO FORMATIVA: ESTRATÉGIA NO ENSINO REMOTO NA PANDEMIA DE COVID-19
}

\author{
(1) JOSÉ PINHEIRO DE QUEIROZ-NETO' \\ (1) ALEXANDRA NASCIMENTO DE ANDRADE" \\ (1) CLISIVÂNIA DUARTE DE SOUZA"II \\ (1) EMANUELLE LORENA TEIXEIRA CHAGASIV
}

\footnotetext{
I Instituto Federal do Amazonas (IFAM), Manaus-AM, Brasil; pinheiro@ifam.edu.br

" Secretaria do Estado de Educação do Amazonas (Seduc/AM), Manaus-AM, Brasil; alexandra_deandrade@hotmail.com

III Instituto Federal do Amazonas (IFAM), Manaus-AM, Brasil; clisivania.duarte@ifam.edu.br

Iv Universidade Federal do Amazonas (UFAM), Manaus-AM, Brasil; emanuelle_chagas@hotmail.com
}

\section{RESUMO}

Este artigo visa a contribuir com alternativas para avaliação educacional no contexto da pandemia de covid-19. Durante o período de isolamento social, os professores passaram a ensinar mediante práticas pedagógicas remotas em caráter emergencial, sobretudo com o uso de tecnologias digitais de informação e comunicação, o que trouxe novos desafios para o processo de ensino e aprendizagem na escola. Entre tais desafios, encontra-se o da avaliação remota, diferente daquela usualmente empregada no ensino presencial. Apresentamos a avaliação formativa como uma estratégia viável nesse contexto, trazendo à discussão conceitos importantes e demonstrando sua efetividade a partir de duas utilizações práticas, com resultados significativos.

PALAVRAS-CHAVE AVALIAÇÃO FORMATIVA • MÉTOdOS DE AVALIAÇÃO • ENSINO PELA INTERNET. 


\section{EVALUACIÓN FORMATIVA: ESTRATEGIA EN EDUCACIÓN REMOTA EN LA PANDEMIA DE COVID-19}

Este artículo tiene como objetivo contribuir a aspectos de la evaluación educativa en el contexto de la pandemia de covid-19. Durante el período de aislamiento social, los maestros comenzaron a enseñar a través de prácticas pedagógicas remotas de emergencia, especialmente con el uso de tecnologías digitales de la información y comunicación, lo que trajo nuevos desafíos al proceso de enseñanza y aprendizaje en la escuela. Entre estos retos se encuentra la evaluación remota, diferente a la que se suele utilizar en la docencia presencial. Presentamos la evaluación formativa como una estrategia y contexto viable, aportando a la discusión conceptos importantes y demostrando su efectividad a partir de dos usos prácticos, con resultados significativos.

PALABRAS CLAVE EVALUACIÓN FORMATIVA • MÉTODOS DE EVALUACIÓN • APRENDIZAJE EN LÍNEA.

\section{FORMATIVE EVALUATION: STRATEGY TO REMOTE EDUCATION IN THE COVID-19 PANDEMIC}

This article aims to contribute to aspects of educational evaluation in the context of the covid-19 pandemic. The period of social isolation made teachers resort to remote pedagogical practices on an emergency basis, particularly the use of digital information and communication technologies, which brought new challenges to the teaching and learning process. Among these challenges is remote evaluation, which is different from that usually used in face-to-face teaching. We present formative evaluation as a viable strategy in this context, bringing to the discussion important concepts and demonstrating its effectiveness based on two practical uses with significant results.

KEYWORDS FORMATIVE EVALUATION • EVALUATION METHODS • ELECTRONIC LEARNING. 


\section{INTRODUÇÃO}

Em março de 2020, o Brasil adotou uma série de medidas em função da pandemia de covid-19, formalizadas pelo Decreto Legislativo n. 6 (BRASIL, 2020b), que reconhece a ocorrência de calamidade pública no país, e mais especificamente para a educação, com a Portaria n. 343 do Ministério da Educação (BRASIL, 2020a), que permitiu a substituição das aulas presenciais pelo ensino remoto emergencial (ERE), enquanto durar a situação de pandemia.

Com a publicação da Medida Provisória n. 934 (BRASIL, 2020c), que estabeleceu normas excepcionais sobre o ano letivo da educação básica e do ensino superior decorrentes das medidas para enfrentamento da situação de emergência de saúde pública, o Instituto Federal do Amazonas (IFAM) deu início à realização de atividades acadêmicas de modo não presencial. A princípio, tal situação se estenderia até dezembro de 2020, mas em virtude do agravamento da pandemia em Manaus e no estado por causa da nova variante P1 do vírus - que levou a um expressivo aumento de óbitos na chamada segunda onda, tornando a cidade notícia no mundo pela falta de oxigênio, leitos, médicos e outros insumos hospitalares -, não havia previsão de retorno às atividades presenciais antes de julho de 2021.

Dessa maneira, as instituições educacionais sofreram uma série de mudanças e de desafios em suas atividades de ensino, pesquisa e extensão. Particularmente no ensino, fez-se necessário repensar práticas pedagógicas em tempos de isolamento social. A pandemia trouxe uma realidade que impôs à escola a quebra de muitos paradigmas, exigindo alunos mais autônomos, professores mais criativos e preparados para uma didática que abarcasse o uso de tecnologias digitais de informação e comunicação (TDIC) (CARVALHO et al., 2019) e uma instituição preparada com recursos tecnológicos e assistência estudantil para redução do impacto das desigualdades sociais.

Dentre tantos desafios, a condição socioeconômica dos alunos impediu, por exemplo, que as aulas fossem exclusivamente on-line, uma vez que a grande maioria dos estudantes de escolas públicas não tinha infraestrutura doméstica para esse tipo de ensino, seja pelo ambiente familiar, pela falta de equipamentos adequados ou simplesmente por não ter acesso à internet de banda larga. Além disso, é importante afirmar que o ERE, como o nome diz, atende a uma situação emergencial.

Coadunamos com o pensamento de Saviani e Galvão (2021, p. 42) ao afirmarem que:

○ "ensino" remoto é empobrecido não apenas porque há uma "frieza" entre os participantes de uma atividade síncrona, dificultada pelas questões tecnológicas. Seu esvaziamento se expressa na impossibilidade de se realizar um trabalho pedagógico sério com o aprofundamento dos conteúdos de ensino, uma vez que essa modalidade não comporta aulas que se valham de diferentes formas de abordagem e que tenham professores e alunos com os mesmos espaços, tempos e compartilhamentos da educação presencial. 
Em meio a esse turbilhão de mudanças em tempo tão ínfimo, os professores se encontraram imersos no ERE, desenvolvendo aulas síncronas (on-line) ou assíncronas (disponíveis para acesso posterior), com o uso de TDIC ou de outras estratégias, como estudo dirigido com material entregue aos alunos. Ao longo desse processo, surgiu, então, a questão relacionada à inquietação sobre como avaliar os alunos no contexto de ERE.

Aqui abrimos um parêntese para deixar claro que aulas em ERE são distintas de aulas no modo educação a distância (EaD), pois esta última, em geral, utiliza-se de um ambiente virtual de aprendizagem (AVA) que foi planejado e projetado para, inclusive, executar a avaliação, com alcance de um público-alvo bem definido, acesso às TDIC e grau de autonomia necessário e suficiente para aulas em EaD.

De maneira geral, os professores tentaram reproduzir em suas aulas no ERE uma "versão on-line" dessa mesma aula com as estratégias antes utilizadas no modo presencial. Não raro, simplesmente filmavam a si mesmos ministrando a aula em um quadro branco ou faziam uso da mesma apresentação em PowerPoint utilizada na aula presencial. Mas como fazer isso com a avaliação, principalmente considerando-se que a maioria dos docentes utiliza um modelo quantitativo, eivado de perguntas e respostas diretas, sejam fechadas ou abertas? Como saber, em uma "prova" remota, se o aluno não vai estar "colando", afinal isso seria relativamente simples?

Nesse sentido, este artigo teve como objetivo trazer à discussão uma alternativa viável para avaliação em tempos de pandemia, que é a avaliação formativa, ou avaliação qualitativa, adequada para processos de aprendizagem com alunos autônomos. Além disso, esse tipo de avaliação requer o comprometimento do professor para aprender acerca do tema e, principalmente, repensar suas práticas pedagógicas, pois traz consigo a necessidade de uma aprendizagem centrada no aluno, na qual este seja sujeito principal do processo, por meio da utilização de metodologias ativas. Essas, por sua vez, vão permitir atividades que facilitam um olhar para uma formação humana integral (BARBOSA; MOURA, 2013) e, portanto, favorecer o ambiente ideal para uma avaliação formativa.

\section{O QUE É UMA AVALIAÇÃO FORMATIVA?}

Assim como os processos de ensino-aprendizagem, a avaliação foi diretamente afetada pelas circunstâncias impostas pela pandemia de covid-19, a qual desafiou professores de todo país a repensarem seu modo não só de ensinar, mas também de avaliar. A imprevisibilidade do momento e os múltiplos modelos existentes de avaliação se mostraram ineficientes diante do quadro de incertezas causado pelo novo cenário educacional. 
A avaliação, enquanto recurso de verificação e aferição da aprendizagem, tem historicamente partido de modelos que priorizam a presencialidade, inclusive em uma perspectiva probatória e, em alguns casos, atribuindo àquela um caráter punitivo e de finalidade do processo de ensino e aprendizagem.

Em 1967, em seu artigo "The methodology of evaluation”, Michael Scriven fez a proposição de distinguir os conceitos de avaliação formativa e avaliação quantitativa (SCRIVEN, 1967). Contudo, foi a partir dos estudos de Benjamin Bloom e seus colaboradores, em 1971 (GUSKEY, 2012), que a avaliação passou a se desenvolver e ter importância no aperfeiçoamento das práticas pedagógicas, tendo sido relacionada com as funções de ajuda, diagnóstico, informação, regulação, diferenciação pedagógica, acompanhamento e envolvimento dos atores (BARREIRA, 2019).

A avaliação formativa tem seu foco no processo de ensino-aprendizagem e está diretamente ligada a ele, constituindo-se em parte de um continuum dele e não em sua finalização. Ela não tem a finalidade de medição da aprendizagem em parâmetros que consideram o quanto se aprendeu, mas sim o que se aprendeu e seu parâmetro qualitativo, ou seja, assume um caráter objetivamente pedagógico.

Buscando identificar dificuldades surgidas ao longo da aprendizagem, a avaliação formativa intenciona a imediata correção das lacunas encontradas. Assim, as práticas docentes vão se ajustando às necessidades objetivas de aprendizagem dos alunos, e não o inverso. A avaliação formativa ou continuada tem função diagnóstica, processual, descritiva e qualitativa. Batista et al. (2007) apontam que a avaliação formativa indica níveis já alcançados pelos alunos no processo de ensino-aprendizagem e estratégias de intervenção necessárias a futuros avanços. Segundo os autores, "[...] envolve, portanto, sistemas mais abertos de avaliação a serviço das orientações das aprendizagens dos alunos e não apenas do registro burocrático de seus resultados” (BATISTA et al., 2007, p. 7).

Tal indicação sinaliza o previsto na Lei de Diretrizes e Bases (LDB) (BRASIL, 1996) sobre avaliação da aprendizagem, ao estabelecer, em seu artigo 24, que a avaliação deve ser contínua e cumulativa, com prevalência dos aspectos qualificativos sobre os quantitativos e dos resultados ao longo do período sobre os de eventuais provas finais. Desse modo, a LDB propõe uma avaliação que se ocupe com os processos de aprendizagem, e não mera certificação/promoção dos alunos à série/ano seguinte.

É objetivo da avaliação formativa proporcionar ao aluno e ao professor um feedback reflexivo sobre o percurso da aprendizagem, considerando nessa reflexão os procedimentos, as metodologias e a possibilidade de diversificação das estratégias utilizadas em função da aprendizagem dos alunos. E aos alunos cabe reflexão sobre os esforços empreendidos e as dificuldades a serem superadas. Assim, em um esforço conjunto, alunos e professores reorientam suas práticas com vistas à melhoria dos resultados alcançados. 
Villas Boas (2009) aponta que, ao se falar de avaliação formativa, tem sido comum o uso de expressões como mediadora, emancipatória, dialógica, fundamentada ou cidadã. Isto é, a avaliação formativa necessita ter um viés que venha a romper com a manutenção do ensino conteudista, que reproduz uma formação dialética capital-trabalho, em uma perspectiva de uma pedagogia libertária, que, para além da formação, vê:

[...] a educação como uma mediação ético-política da formação humana que possibilita a compreensão da realidade e potencializa a ação dos sujeitos para superar a exploração e a alienação dos trabalhadores, transformando-a em benefício da emancipação humana. (RAMOS, 2010, p. 71).

A situação atual trouxe ao professor inquietações no que se refere ao seu modus operandi, visto que a aprendizagem, para além das metodologias utilizadas, perpassa pelas avaliações empregadas. É importante compreender que estas não são um fim em si mesmas, mas fazem parte do processo e, assim, de forma cíclica, seus resultados deveriam representar uma retomada de novos caminhos de aprendizagem, revendo-os ou redirecionando-os a um novo ciclo. Segundo Vasconcellos (2007), a avaliação formativa exige uma mudança de postura por parte do professor, pois ele precisará dedicar seus esforços à aprendizagem do aluno, e não ao conteúdo que ele supõe ter transmitido.

Portanto, para além das inquietações, o novo contexto educacional provocou a necessidade de um movimento que direcionasse o professor à criatividade, a novas possiblidades e à busca de soluções inovadoras para o ensino, especialmente porque o ERE, mediado pelas tecnologias, requer do docente uma nova postura para ensinar e avaliar.

Nesse sentido é que deve a escola, em especial a pública, considerar as fissuras sociais expostas no atual contexto e desenvolver ações para se manter essencialmente inclusiva e equânime. Assim, compreende-se que a avaliação formativa é parte de uma resposta que contribui para tal realidade.

\section{PRÁTICAS PEDAGÓGICAS NA/PARA AVALIAÇÃO FORMATIVA NO ERE}

$O$ atual quadro social de pandemia requer de professores um movimento no sentido de rever suas práticas de ensino buscando otimizar tempos e espaços formativos, com foco na criatividade e em adequações tecnológicas necessárias para atuar no ERE em períodos longos que trazem a necessidade das avaliações, inclusive, para atribuição de notas.

A pandemia trouxe consigo desafios a diversos profissionais, que tiveram de se "reinventar" para atender às demandas propostas pelo ERE. Práticas típicas de cursos de áreas tecnológicas passaram a fazer parte do cotidiano das escolas regulares e, no caso em questão, dos cursos de educação profissional. 
A educação profissional segue, mesmo em tempos de pandemia, como "[...] elemento estratégico para a construção da cidadania e para a melhor inserção de jovens e trabalhadores na sociedade contemporânea, plena de grandes transformações e marcadamente tecnológica” (BRASIL, 2004, p. 7) e ainda como instituição pública comprometida com um fazer pedagógico que priorize a formação humana e integral, tendo como fio condutor sua preparação para a continuidade de estudos e ao mesmo tempo para o mundo do trabalho.

Nesse sentido, no IFAM intensificaram-se processos formativos para os docentes, focados em estudos sobre as tecnologias interativas de aprendizagem e o ensino híbrido, ambos centrados nas metodologias ativas como percurso metodológico necessário à educação humana e integral, compromisso institucional da Rede Federal de Educação Profissional e Tecnológica.

Fachineto et al. (2020, p. 7) destacam que a avaliação formativa é imprescindível no ensino on-line, "[...] caminho a ser trilhado na construção e reflexão do conhecimento, no respeito ao saber e ao cotidiano dos alunos [...] oferecendo feedback, flexibilidade na data de realização das atividades, respeitando o ritmo individual do aluno". Nesse tipo de avaliação, uma maneira de registrar as atividades seria a utilização, por exemplo, de mapas cognitivos, memoriais, blogs, fóruns de discussão e webfólios.

A integração das TDIC nas atividades de sala de aula tem proporcionado, ou pelo menos facilitado, o ensino híbrido, sendo que a "sala de aula invertida" é uma das modalidades que têm sido inseridas tanto no ensino básico quanto no ensino superior (OLIVEIRA et al., 2021, p. 3).

$\mathrm{Na}$ aplicação do ERE, as TDIC se mostraram ferramenta importante, senão fundamental. Contudo, elas não podem constituir a única possibilidade para a educação remota, uma vez que o acesso às TDIC não é universal.

\footnotetext{
Assim, estruturas como as oferecidas pelo Google, Google Classroom, Meet Google; WhatsApp; Zoom, Google Chrome, entre outras, passaram a fazer parte do universo escolar, exigindo do docente um ressignificar sobre sua prática pedagógica. Diferente do que muitos pensam, o processo não se resumia tão somente a capacitação do docente em metodologias ativas, como se pensou à época. Afinal, era importante pensar acerca da capacidade do educador, ora creditada à presença física do educando, em relação à iniciativa diante da perspectiva da mudança em relação ao sentido do educar. (MONTEIRO, 2020, p. 18).
}

A necessidade de reinvenção da escola foi duramente evidenciada, inclusive no que se refere às relações entre professor e aluno e às metodologias que têm sido aplicadas nesse processo. Dentre as possibilidades de reinvenção do trabalho educativo, ampliou-se a utilização das metodologias ativas como caminho pedagógico na superação das dicotomias presentes no novo cenário escolar. 
O termo "metodologias ativas de aprendizagem", apesar da intensificação de uso nesses tempos, não é novidade ao professorado que atua na rede federal. O desenvolvimento de trabalhos pedagógicos com projetos integradores e a articulação entre ensino, pesquisa e extensão já evidenciam práticas pedagógicas que pressupõem engajamento efetivo em processos ativos de aprendizagem. É importante reforçar que o uso das metodologias ativas se situa para além de didáticas com TDIC, envolvendo processos de aprendizagem que possibilitam aos alunos estarem "ativamente envolvidos" (BARBOSA; MOURA, 2013, p. 54).

Oliveira, Cruz e Nascimento (2020) demonstram que as TDIC já foram empregadas para realizar a avaliação formativa, utilizando como metodologia ativa a aprendizagem baseada em problema, em um estudo de caso de estudo autodirigido. Pascoalino (2021) esclarece o quanto as metodologias ativas podem ser facilitadoras no ERE, ao utilizarem a aprendizagem baseada em projetos aplicada à disciplina de Física no ensino médio, com excelentes resultados.

Assim, a aprendizagem por metodologias ativas ocorre quando o aluno rompe com uma postura passiva diante do aprendizado e interage com ele, indagando, ouvindo, refletindo e construindo os processos de aprendizagem. O aluno deixa de assumir uma postura de receptor e passa a ser protagonista de sua própria aprendizagem. É nesse momento que a avaliação formativa tem uma aplicação mais efetiva. Segundo Ribeiro (2005), e a partir de suas experiências, a aprendizagem é mais significativa com o uso das metodologias ativas de aprendizagem. Conforme o autor, alunos que vivenciam essas metodologias desenvolvem a confiança em suas decisões e no uso do conhecimento em situações do mundo real, melhoram o relacionamento interpessoal, aprendem a se comunicar melhor oralmente e por escrito e se percebem motivados para resolver problemas e vivenciar situações que requerem tomar suas próprias decisões, reforçando a autonomia no modo de pensar e atuar.

Tais ponderações sobre as metodologias ativas enquanto recurso de ensino e aprendizagem levam a uma reflexão sobre os processos avaliativos a serem empregados a partir desse pressuposto, visto que é imperioso que a avaliação seja considerada como continuidade desse processo e não um fim em si mesma, isolada e intencionada à aferição de resultados probatórios. E a avaliação necessária à continuidade de práticas embasadas nas metodologias ativas é a que se faz a partir de uma perspectiva formativa, com o aluno no centro do processo, compreendendo sua formação como parte de um constructo voltado à formação humana e integral, para além dos conteudismos e ensinos propedêuticos (GADOTTI, 1994).

Praticas pedagógicas ativas são, de fato, facilitadoras para a avaliação formativa, contudo isto exige um repensar da prática docente. Tal mudança se dá por meio da construção de processos de formação para os professores, coordenadores de curso e tutores, a partir de um modelo de emancipação (PASCHOALINO; RAMALHO; 
QUEIROZ, 2020). Segundo Fernandes (2005, p. 7): “A avaliação formativa deve permitir conhecer bem os saberes, as atitudes, as capacidades e o estágio de desenvolvimento dos alunos, ao mesmo tempo que deve proporcionar-lhes indicações claras acerca do que é necessário fazer a seguir".

As análises aqui expostas permitem a correlação do estudo das metodologias ativas e avaliação formativa com o proposto por Ciavatta (2005) ao refletir sobre formação humana e integral, reiterando que a escola não pode estar alheia às necessidades materiais para levar adiante um processo educacional completo e efetivo. A escola deve estar atenta, primeiro, às necessidades dos alunos no cumprimento de um percurso de estudos para se manterem na escola, e, como elemento aglutinador, gerador de coesão social, deve assumir-se como um lugar de memória, de resgate das identidades, da compreensão do presente incorporando as dificuldades, superando-as.

\section{EXPERIÊNCIAS DE AVALIAÇÃO FORMATIVA NO IFAM}

E como utilizar essa avaliação formativa com o uso de metodologias ativas? Para além dos aspectos conceituais, e como contribuição para motivar os professores ao uso da avaliação formativa no ERE, particularmente em tempos de pandemia, trazemos dois exemplos de uso dela no Instituto Federal do Amazonas. Ambas se deram no período da pandemia e nelas se percebe o uso de metodologias ativas, sem as quais se tornaria difícil a avaliação formativa, devido à imperiosidade de aulas não presenciais.

É importante frisar que essas experiências são demonstrações da aplicabilidade da avaliação formativa, que podem servir como exemplos, e não necessariamente como modelos. Cabe ao professor construir suas próprias estratégias de avaliação formativa, considerando os conteúdos envolvidos, a maturidade da turma, o prazo, as condições de acesso e demais questões envolvidas.

A primeira experiência se dá no âmbito de um projeto de extensão e internacionalização, e a segunda na disciplina Introdução à Engenharia de Controle e Automação, integrante da grade curricular do curso de Engenharia de Controle e Automação (Ecat).

\section{O projeto Lapassion}

Em 2018, o IFAM iniciou uma parceria com instituições nacionais, latino-americanas e europeias, em um projeto intitulado Latin America Practices and Soft Skills for an Innovation Oriented Network (Lapassion), com recursos oriundos do Programa Erasmus Plus, da União Europeia. O projeto Lapassion é coordenado pelo Instituto Politécnico do Porto (IPP) e conta com uma instituição finlandesa - Universidade 
de Ciências Aplicadas de Tampere (TAMK) -; duas espanholas - Universidade de Vigo e Universidade de Salamanca -; duas chilenas - Departamento Universitario Obrero Campesino de la Universidad Católica (DUOC-UC) e Pontificia Universidad Católica de Chile (PUC); duas uruguaias - Universidad de la República (Udelar) e Universidade Técnica de Uruguay (UTEC) -; e cinco brasileiras - IFAM, Instituto Federal de Educação, Ciência e Tecnologia do Maranhão (IFMA), Instituto Federal de Educação, Ciência e Tecnologia de Goiás (IFG), Instituto Federal de Educação Ciência e Tecnologia do Triângulo Mineiro (IFTM) e Instituto Federal de Educação, Ciência e Tecnologia Sul-Riograndense (IFSul). O projeto proporcionou o intercâmbio de alunos de ensino superior, orientados por professores e parceiros externos, para atuarem em projetos nos quais foram formadas equipes com alunos de cursos e países diferentes. As equipes atuaram durante 10 semanas para apresentar uma solução a um desafio proposto por um parceiro externo, dentro de um tema previamente definido. O idioma oficial do projeto foi o inglês.

O projeto teve versões no Chile, Uruguai e Brasil (nos estados de Maranhão, Minas Gerais e Goiás), e no período de 2 de março a 8 de maio de 2020 ocorreu o evento Lapassion Manaus, cujo tema foi "Tecnologias socioambientais para a sustentabilidade da Amazônia”. Em Manaus, o projeto recebeu 8 alunos do exterior (2 da Finlândia, 2 de Portugal e 4 do Chile) e 6 de institutos federais brasileiros (Piauí, Pará, Rondônia, Pernambuco, Amapá e Alagoas). Na terceira semana do projeto, as atividades presenciais foram suspensas devido à pandemia.

Utilizando como metodologia ativa uma integração da aprendizagem baseada em projetos (QUEIROZ-NETO, 2017) com o design thinking (FARIAS, 2019), o Lapassion apresentou três fases: imersão, ideação e prototipação. A imersão foi destinada a estudar o problema proposto pelas empresas sob diferentes perspectivas, a partir do levantamento, seleção, organização e análise de informações; na ideação, resgataram-se as informações obtidas na fase de imersão a fim de gerar ideias que colaborassem para a solução do problema proposto; e a fase de prototipação tratou da transformação das ideias em planos de ações ou protótipos: um artefato, por meio de representação conceitual ou análoga, que fosse referência para uma futura construção de um produto final.

O método de avaliação formativa se deu em duas etapas: (i) avaliações parciais semanais e (ii) avaliação final. As avaliações parciais foram executadas todas as sextas-feiras, por meio do aplicativo Google Meet, que permite a realização de webconferências com até 255 pessoas. Nelas, os alunos apresentavam, em equipe, a evolução da aprendizagem e do desenvolvimento do projeto naquela semana. Professores orientadores faziam questionamentos e sugeriam ajustes a todos os grupos, independentemente de serem orientadores ou não daquele grupo, e ao final se reuniam para avaliar o desenvolvimento coletivo e individual dos alunos. 
A avaliação final se deu na última semana do projeto, mediante webconferência via Google Meet, dessa vez aberta ao público e aos pares externos (empresas) e internos (universidades envolvidas no Lapassion), em um evento chamado pelo projeto de DemoDay. Cada equipe apresentou duas vezes seu resultado final, sendo uma apresentação em inglês e outra em português. A avaliação formativa, portanto, consistiu em todo o desenvolvimento do processo e seu resultado final. Não se avaliou necessariamente o protótipo desenvolvido, mas efetivamente a aprendizagem de cada aluno. Não houve nota final (quantitativa) e todos foram aprovados, sendo registrada uma única desistência, por motivo de saúde familiar (contágio por covid-19).

A Figura 1 apresenta dois momentos do projeto: em (a) uma das avaliações semanais e em (b) a avaliação final no DemoDay. É possível observar na Figura 1(a) que, mesmo em uma atividade remota com TDIC, as atividades práticas do projeto foram executadas e avaliadas, quebrando o paradigma de que não é possível atividade prática no ERE. O resultado final, apresentado na Figura 1(b), foi adotado pela Secretaria de Estado do Meio Ambiente do Amazonas (Sema) e se tornou um produto, ou seja, além do aspecto formativo, ainda proporcionou benefícios à comunidade.

\section{FIGURA 1 - Avaliação formativa no projeto Lapassion}

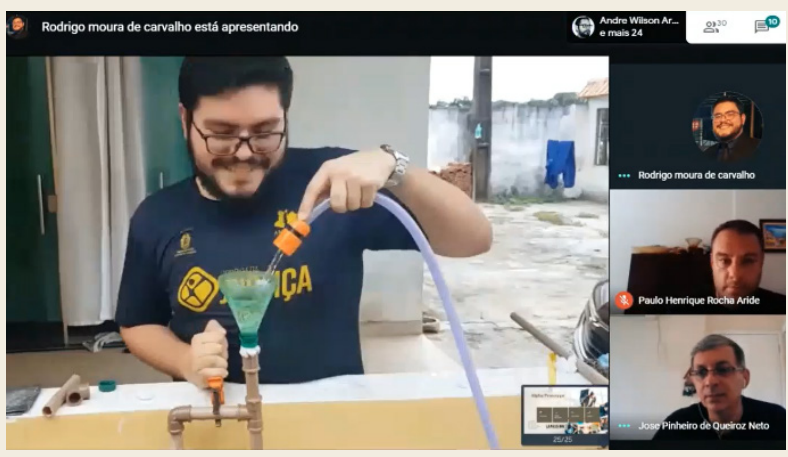

(a) Avaliação semanal

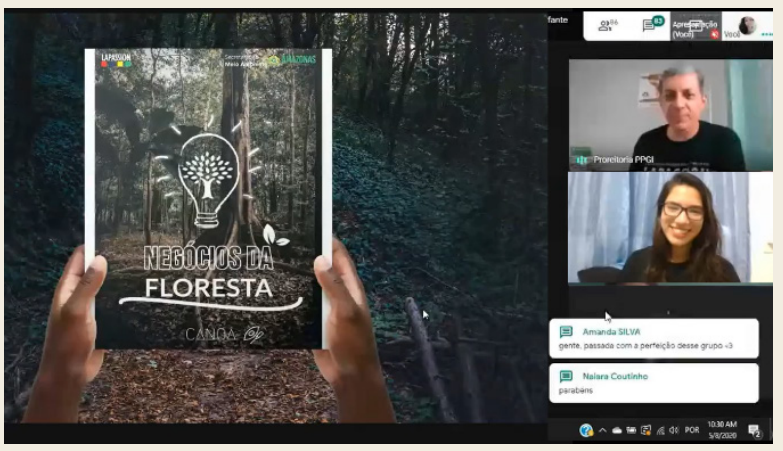

(b) DemoDay

Fonte: Acervo pessoal (2020). Uso de imagens autorizadas.

\section{Uso em uma disciplina técnica}

Iniciada em fevereiro de 2020, a disciplina Introdução à Engenharia de Controle e Automação, oferecida no primeiro período do curso de Engenharia de Controle e Automação, do campus Manaus Distrito Industrial do IFAM, também enfrentou o revés da pandemia, com suas atividades presenciais suspensas em março e reiniciadas em agosto de 2020, em modo não presencial. O professor da disciplina já tinha formação em metodologias ativas e avaliação formativa, resultado de sua participação no programa Professores para o Futuro ${ }^{1}$ - Edital Setec/MEC n. 15/2014 -

1 Em inglês, VET - Teachers for the Future. 
o qual frequentou durante cinco meses na Tampere University of Applied Sciences, na cidade de Tampere, Finlândia.

A disciplina utilizou como metodologia ativa a aprendizagem baseada em projeto, ou project based learning (PBL) (QUEIROZ-NETO, 2017). Existem cinco critérios necessários a um projeto que respondem essa questão: o foco, a orientação, as investigações construtivas, a autonomia e o realismo (KOKTSAKI; MENZIES; WIGGINS, 2016). Na PBL, os projetos são a estratégia central de ensino. Nela, os alunos desenvolvem os principais conceitos da disciplina ao se organizarem em equipes para desenvolverem projetos. Para atingir o objetivo, os projetos estão relacionados aos conteúdos da disciplina e são direcionados a problemas que levam os discentes a desenvolverem conceitos, princípios básicos e habilidades de determinado tópico, envolvendo, ainda, processos de investigação.

A avaliação formativa se deu concomitantemente com os projetos que foram desenvolvidos. Nesse caso, o professor apresentou três oportunidades de projetos, que abrangeram os principais conteúdos da disciplina: sensores, atuadores e sistemas automatizados. Cada projeto teve duração de duas semanas. Ao término da primeira semana, o professor separou um tempo de uma das aulas para uma avaliação parcial conjunta do andamento do trabalho, em uma "roda de conversa virtual" com a turma. Ao término da segunda semana, cada equipe apresentava à turma o resultado final do projeto, que era questionado pelas demais equipes e pelo próprio professor, sempre em uma avaliação propositiva, visando a melhorias para trabalhos futuros e mantendo a motivação da equipe.

É importante ressaltar que o professor utilizou como estratégia de ERE aulas síncronas (com participação on-line dos alunos via Google Meet) e assíncronas (aula gravada e disponibilizada em canal do YouTube, com possibilidade de acesso dos alunos). Isso permitia que alunos com dificuldades de acesso síncrono pudessem assistir à aula dentro de suas possibilidades de tempo e de acesso à internet. Assim, as avaliações dos projetos utilizaram estratégia semelhante, tendo a maioria das equipes gravado um vídeo de 3 a 5 minutos com os conceitos e a parte prática do projeto. Isso resguardava eventuais problemas de acesso ou de internet dos alunos, pois os materiais já haviam sido enviados antecipadamente para o professor, que poderia exibir, de seu computador, o vídeo para o restante da turma presente.

As notas da disciplina, necessárias nesse caso em função dos regulamentos internos do IFAM, foram atribuídas com base no desenvolvimento dos projetos e na apresentação final, com os seguintes critérios explicitados anteriormente pelo professor: (i) domínio do assunto; (ii) qualidade e clareza do vídeo ou apresentação; (iii) grau de dificuldade do exemplo prático; (iv) funcionalidade do exemplo prático.

Dos 28 alunos que reiniciaram a disciplina em agosto, após meses de suspensão das aulas, 27 a concluíram com sucesso e somente um se evadiu, por motivo 
de falecimento de familiares por complicações de infecção por covid-19. A Figura 2 apresenta dois momentos do projeto: em (a) uma das apresentações do primeiro projeto e em (b) uma das apresentações do terceiro projeto. Em ambos os casos, o que se apresenta na Figura 2 é um print (instantâneo da tela do computador) do vídeo produzido e apresentado pelos alunos.

FIGURA 2 - Avaliação formativa na disciplina Introdução a Engenharia/ECAT

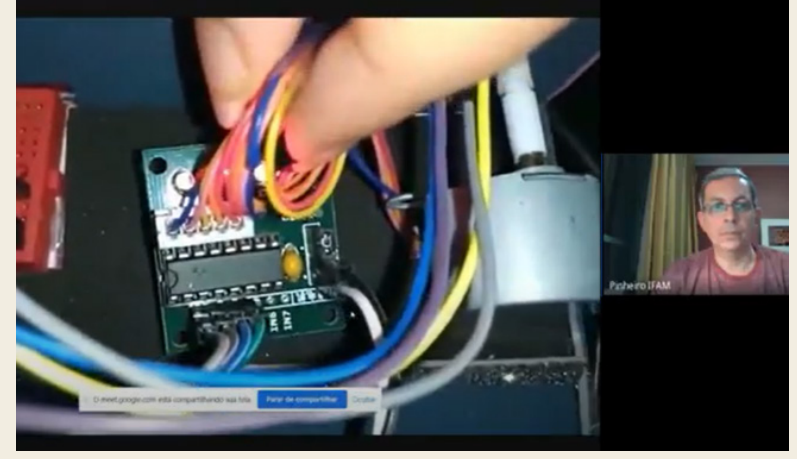

(a) Apresentação do primeiro projeto

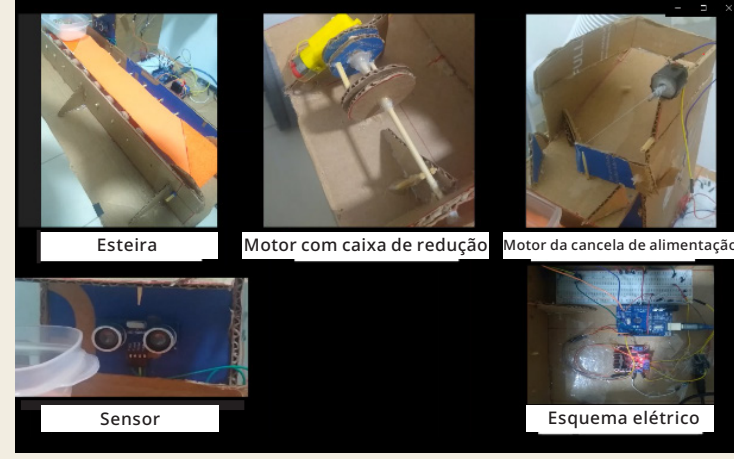

(b) Apresentação do terceiro projeto

Fonte: Acervo pessoal (2020). Uso de imagens autorizadas.

\section{CONSIDERAÇÕES FINAIS}

Por que avaliar? Que modelos e práticas alicerçam o ato avaliativo? Decorrentes desses, é possível que surjam outros questionamentos, tais como: o que se tem de avaliar? A quem se tem de avaliar? Como se deve avaliar? Essas são questões que muitas vezes inquietam, pois trazem consigo um repensar não somente do ato avaliativo em si, mas também da práxis educativa ao qual se encontra atrelada.

Ao refletir sobre metodologias ativas e avaliação formativa, evidencia-se o necessário redimensionamento do papel do professor, que, nesse novo contexto de ERE, não pode representar mais o detentor do saber e um verificador de aprendizagens, mas passa a ser alguém que, traçando os caminhos que conduzem à construção da aprendizagem, posiciona-se também como aprendiz, disposto a possibilitar aos seus alunos experiências que favoreçam a resolução de problemas e o pensamento crítico. Zabala (1998, p. 12) reitera que "[...] a tomada de posição em relação às finalidades do ensino, relacionada a um modelo centrado na formação integral da pessoa, implica mudanças fundamentais, especialmente nos conteúdos e no sentido da avaliação”.

Assim, a avaliação formativa detém sentidos que atendem ao que se intitulou de "nova normalidade", exigindo dos docentes mais que um repensar de suas práticas: um agir nessa direção onde o ensino, remodelado e ajustado aos novos tempos, possa favorecer um clima de confiança entre aluno e professor, para que, dessa 


\section{forma, a avaliação enquanto parte de um ciclo represente também um momento de aprendizagem.}

\section{REFERÊNCIAS}

BARBOSA, E. F.; MOURA, D. G. Metodologias ativas de aprendizagem na Educação Profissional e Tecnológica. Boletim Técnico do Senai, Rio de Janeiro, v. 39, n. 2, p. 48-67, maio/ago. 2013.

BARREIRA, C. Concepções e práticas de avaliação formativa e sua relação com os processos de ensino e aprendizagem. In: ORTIGÃO, M. I. R.; FERNANDES, D.; PEREIRA, T. V.; SANTOS, L. Avaliar para aprender no Brasil e em Portugal: perspectivas teóricas, práticas e de desenvolvimento. Curitiba: CRV, 2019. p. 191-218. DOI: 10.248224/978854443463.5.

BATISTA, A. G. B.; SILVA, C. S. R.; BREGUNCI, M. G.; VAL, M. G. F. C.; CASTANHEIRA, M. L.; MONTEIRO, S. M.; FRADE, I. C. A. S. Pró-Letramento: Programa de Formação Continuada de Professores dos Anos/Séries Iniciais do Ensino Fundamental: alfabetização e linguagem: formação de professores. ed. rev. e ampl. Incluindo Saeb/Prova Brasil matriz de referência. Brasília: MEC/SEB, 2007. (Fascículo 2: Alfabetização e letramento: questões sobre avaliação).

BRASIL. Lei n. 9.394, de 20 de dezembro de 1996. Estabelece as diretrizes e bases da educação nacional. Brasília: Presidência da República, 1996. Disponível em: http://www.planalto.gov.br/ccivil_03/leis/19394.htm. Acesso em: out. 2020.

BRASIL. Ministério da Educação. Secretaria de Educação Profissional e Tecnológica. Políticas públicas para a educação profissional e tecnológica: proposta em discussão. Brasília: MEC; Setec, 2004. Disponível em: http://portal.mec.gov.br/setec/arquivos/pdf/p_publicas.pdf. Acesso em: out. 2020.

BRASIL. Portaria n. 343, de 17 de março de 2020. Dispõe sobre a substituição das aulas presenciais por aulas em meios digitais enquanto durar a situação de pandemia do Novo Coronavírus covid-19. Brasília: Ministério da Educação, 2020a.

BRASIL. Decreto Legislativo n. 6, de 20 de março de 2020. Reconhece, para os fins do art. 65 da Lei Complementar n. 101, de 4 de maio de 2000, a ocorrência do estado de calamidade pública, nos termos da solicitação do Presidente da República encaminhada por meio da Mensagem n. 93, de 18 de março de 2020. Brasília: Senado Federal, 2020b.

BRASIL. Medida Provisória n. 934, de $1^{\circ}$ de abril de 2020. Estabelece normas excepcionais sobre o ano letivo da educação básica e do ensino superior decorrentes das medidas para enfrentamento da situação de emergência de saúde pública de que trata a Lei n. 13.979, de 6 de fevereiro de 2020. Brasília: Presidência da República, 2020c.

CARVALHO, L. A. de; SANTOS, S. F. dos; OLIVEIRA, L. F. P.; GALDINO, M. E. R. Tecnologias digitais de informação e comunicação (TDIC’s) e a sala de aula. Perspectivas Online: Humanas \& Sociais Aplicadas, Campos dos Goytacazes, RJ, v. 9, n. 26, p. 32-51, set./dez. 2019.

CIAVATTA, M. A formação integrada: a escola e o trabalho como lugares de memória e de identidade. Trabalho Necessário, Niterói, RJ, v. 3, n. 3, p. 1-20, 2005. Disponível em: http://periodicos.uff.br/trabalhonecessario/article/view/6122/5087. Acesso em: out. 2020. 
FACHINETO, S.; SCANTAMBURLO, E. L. R.; ZANGALLI, L. C.; KOHNLEIN, J. T. C. Avaliação de aprendizagem em meio a pandemia do coronavírus no Brasil. Anuário Pesquisa e Extensão Unoesc São Miguel do Oeste, Joaçaba, SC, v. 5, e24090, 2020.

FARIAS, M. S. F. Design thinking na elaboração de um produto educacional: roteiro de aprendizagem - estruturação e orientações. 2019. 157 f. Dissertação (Mestrado Profissional em Ensino Tecnológico) - Instituto Federal de Educação, Ciência e Tecnologia do Amazonas, Manaus, 2019.

FERNANDES, D. Avaliação alternativa: perspectivas teóricas e práticas de apoio. In: CONGRESSO INTERNACIONAL SOBRE AVALIAÇÃO NA EDUCAÇÃO, 3., 2005, Curitiba. Anais [...]. Curitiba: Futuro Congressos e Eventos, 2005. p. 79-92.

GADOTTI, M. História das ideias pedagógicas. 2. ed. São Paulo: Ática, 1994.

GUSKEY, T. R. Benjamin S. Bloom: portraits of an educator. Lanham: R\&L Education, 2012.

KOKTSAKI, D.; MENZIES, V.; WIGGINS, A.; Project-based learning: a review of the literature. Improving Schools, v. 19, n. 3, p. 267-277, July 2016. DOI: 10.1177/1365480216659733.

MONTEIRO, M. O. Avaliação em tempos de pandemia: uma abordagem holística do processo. Revista Transformar, Itaperuna, RJ, v. 14, Edição Especial “Covid-19: pesquisa, diálogos transdisciplinares e perspectivas”, p. 6-27, maio/ago. 2020.

OLIVEIRA, A.; OLIVEIRA, C. J. O ensino remoto durante a pandemia de covid-19: sala de aula invertida e o uso das tecnologias digitais de informação. In: SIMPÓSIO DE PESQUISA E DE PRÁTICAS PEDAGÓGICAS DO UGB, 9., 2021, Volta Redonda, RJ. Anais [...]. Volta Redonda, RJ: UGB, 2021. Disponível em: http://revista.ugb.edu.br/ojs302/index.php/simposio/article/view/2335. Acesso em: mar. 2021.

OLIVEIRA, F. M.; CRUZ, R. R. S.; NASCIMENTO, T. A. Uso das tecnologias digitais no contexto da aprendizagem autodirigida integrada à avaliação formativa alternativa. In: ENCONTRO DE INTEGRAÇÃO DA EDUCAÇÃO A DISTÂNCIA DA UFMS, 3., 2020, Campo Grande. Anais [...]. Campo Grande: UFMS, 2020. p. 1-15.

PASCHOALINO, J. B. Q.; RAMALHO, M. L.; QUEIROZ, V. C. B. Trabalho docente: o desafio de reinventar a avaliação em tempos de pandemia. Labor, Fortaleza, v. 1, n. 23, p. 113-130, jan./jun. 2020.

PASCOALINO, K. C. Da S. Metodologias ativas como facilitadoras do ensino remoto devido a pandemia de Covid-19: estudo de caso aplicado à disciplina de Física no ensino médio. Estudose Negócios Acadêmicos, Santo André, SP, v. 1, n. 1, p. 45-56, jan./jul. 2021.

QUEIROZ-NETO, J. P. Quebrando paradigmas para melhorar a aprendizagem na educação professional tecnológica do Instituto Federal do Amazonas. In: MÄLLINEN, S.; PROKKI, C. Brazil meets Finland: experiências em metodologias centradas no estudante baseadas em práticas finlandesas. Tampere: Writers and Tampere; University of Applied Sciences, 2017. p. 53-69.

RAMOS, M. Trabalho e educação no Brasil: um estudo a partir da formação de trabalhadores técnicos da Saúde. Rio de Janeiro: Editora da UFRJ; Escola Politécnica de Saúde Joaquim Venâncio/ Fiocruz, 2010.

RIBEIRO, L. R. C. A aprendizagem baseada em problemas (PBL): uma implementação na educação 
em engenharia na voz dos atores. 2005. 236 f. Tese (Doutorado em Educação) - Universidade Federal de São Carlos, São Carlos, SP, 2005.

SAVIANI, D.; GALVÃO A. C. Educação na pandemia: a "falácia" do ensino remoto. Universidade e Sociedade, Brasília, v. 31, n. 67, p. 36-49, jan. 2021.

SCRIVEN, M. The methodology of evaluation. In: TYLER, R. W.; GAGNE, R. M.; SCRIVEN, M. (ed.). Perspectives of curriculum evaluation. Chicago: Rand McNally, 1967. p. 39-83.

VASCONCELLOS, C. dos S. Avaliação: concepção dialética libertadora do processo de avaliação escolar. 17. ed. São Paulo: Libertad, 2007.

VILLAS BOAS, B. M. de F. (org.). Virando a escola do avesso por meio da avaliação. 2. ed. Campinas, SP: Papirus, 2009. (Coleção Magistério: Formação e Trabalho Pedagógico).

ZABALA, A. A prática educativa: como ensinar. Porto Alegre: Artmed, 1998.

NOTA: José Pinheiro de Queiroz-Neto é o autor principal, que conduziu e executou a pesquisa de campo com as duas turmas da aplicação da avaliação formativa no ERE; Alexandra Nascimento de Andrade desenvolveu a revisão bibliográfica e os conceitos da avaliação formativa; Clisivânia Duarte de Souza desenvolveu o texto sobre as práticas pedagógicas de avaliação formativa no ERE; Emanuelle Lorena Teixeira Chagas, tendo como objeto de pesquisa de mestrado o projeto Lapassion, contribuiu com os dados sobre avaliação formativa desse projeto.

\section{COMO CITAR ESTE ARTIGO}

QUEIROZ-NETO, José Pinheiro de; ANDRADE, Alexandra Nascimento de; SOUZA, Clisivânia Duarte de; CHAGAS, Emanuelle Lorena Teixeira. Avaliação formativa: estratégia no ensino remoto na pandemia de covid-19. Estudos em Avaliação Educacional, São Paulo, v. 33, e08463, 2022.

DOI: https://doi.org/10.18222/eae.v33.8463

Recebido em: 13 MARÇO 2021

Aprovado para publicação em: 28 outubro 2021

Este é um artigo de acesso aberto distribuído nos termos da licença Creative Commons do tipo BY-NC. 